\title{
Erratum to: Structural, thermal and antibacterial properties of polyamide 11/polymeric biocide polyhexamethylene guanidine dodecylbenzenesulfonate composites
}

Sergiy Rogalsky ${ }^{1, *}$, Jean-Francois Bardeau ${ }^{2}$, Hao $\mathrm{Wu}^{3}$, Lyudmila Lyoshina ${ }^{4}$, Olga Bulko ${ }^{4}$, Oksana Tarasyuk ${ }^{1}$, Stanislav Makhno ${ }^{5}$, Tetiana Cherniavska ${ }^{5}$, Yuriy Kyselov ${ }^{1}$, and Joseph $\mathrm{H} . \mathrm{Koo}^{3}$

${ }^{1}$ Institute of Bioorganic Chemistry and Petrochemistry of National Academy of Science of Ukraine, 50 Kharkivske Schose, Kyiv 02160, Ukraine

${ }^{2}$ Institut des Molécules et Matériaux du Mans, Université du Maine, Avenue Olivier Messiaen, UMR CNRS 6283, 72085 Le Mans Cedex 9, France

${ }^{3}$ The University of Texas at Austin, Texas Materials Institute/Center for Nano and Molecular Science and Technology, 204 E Dean Keeton St., C2200, Austin, TX 78712-0292, USA

${ }^{4}$ Institute of Cell Biology and Genetic Engineering of National Academy of Science of Ukraine, 148 Academika Zabolotnoho Str., Kyiv 03143, Ukraine

${ }^{5}$ Chuiko Institute of Surface Chemistry of National Academy of Sciences of Ukraine, 17 General Naumov Str, Kyiv 03680, Ukraine

\section{Published online:}

5 July 2016

(C) Springer Science+Business Media New York 2016
Erratum to: J Mater Sci (2016) 51:7716-7730 DOI 10.1007/s10853-016-0054-X

There were two errors in the article abstract. Instead of Gram-positive (Escherichia coli) it should read Gram-negative (Escherichia coli); instead of Gram- negative (Bacillus subtilis) it should read Gram-positive (Bacillus subtilis). The authors were solely responsible for these errors and regret any confusion they may have caused.

The online version of the original article can be found under doi:10.1007/s10853-016-0054-x.

Address correspondence to E-mail: sergey.rogalsky@gmail.com 